Revista Estudios, (37), 2018.

Diciembre 2018-Mayo 2019

ISSN 1659-3316

Fallas Vargas Fabrizio

III Sección: Sobre conceptos categorías, mitos y realidades

\title{
La Imagen Dialéctica como categoría relevante para las constelaciones de una dialéctica negativa en GOYA, GROSZ Y BENJAMIN/KLEE
}

\author{
Fabrizio Fallas-Vargas \\ Instituto Tecnológico de Costa Rica (TEC), Costa Rica \\ fv.fabrizius@gmail.com \\ https://orcid.org/0000-0002-8837-2516
}

Recibido: 25 de setiembre de 2018

Aceptado: 30 de octubre de 2018

Resumen: Se explora en este trabajo la categoría de imagen dialéctica como dispositivo analítico crítico-práxico, al interior del cual se articulan en forma constelacional elementos alegóricos, gráficos y especialmente conceptuales que apuntan al desarrollo de una skepsis materialista en tanto que componente de una dialéctica negativa/adorniana. Los soportes somáticos para la realización de esta pesquisa, a saber: Capricho No. 43 (1799) de Goya, Los pilares de la sociedad (1926) de Grosz y La Tesis IX sobre Filosofía de la Historia, a propósito de Angelus Novus, Benjamin/Klee (1940/1920) constituyen por propio derecho modelos de intervención que declinan sin ambages el ocultamiento, neutralización y/o desplazamiento de sus condiciones materiales/históricas de producción y en tal sentido proceden al desmontaje de una forma de racionalidad mistificada que se asume y promueve a sí misma como destino incontrastable e incontestable en el orden de "la" cultura.

Palabras clave: Imagen dialéctica; Dialéctica Negativa; Adorno; Benjamin; Constelaciones; Klee.

The Dialectic Image as a relevant category towards negative dialectics constelations: GOYA, GROSZ AND BENJAMIN / KLEE

Abstract: In this paper, the category of the dialectical image is explored as an analytical device. At a critical / praxical level, within this device, allegorical, graphic and especially conceptual elements are related to each other to develop a

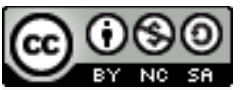

La Revista Estudios es editada por la Universidad de Costa Rica y se distribuye bajo una Licencia Creative Commons Atribución-NoComercial-CompartirIgual 3.0 Costa Rica. Para más información envíe un mensaje a revistaestudios.eeg@ucr.ac.cr. 
materialistic skepsis (a sine qua non component of constellations within dialectic's in it's negative/adornian expression). Somatic supports shown for this research are: Goya's Caprice 43 (1799), Grosz's The pillars of society (1926) and Benjamin's Philosophy of History (Thesis IX), regarding Angelus Novus, Benjamin / Klee (1940/1920). Each one and by its own right can be seen from an adornian insight as intervention models that unequivocally reject the concealment, neutralization and / or displacement of its material / historical production conditions and therefore, they proceed to the dismantling of a mystified form of rationality that assumes and promotes the order of "the" culture as an incontrastable reality and fatal destiny.

Keywords: Dialectic Images; Negative Dialectics; Adorno; Benjamin; Constelations, Klee.

"Lo más propio de la experiencia dialéctica es que disipa la apariencia ilusoria del siempre-lo-mismo, en realidad incluso de la simple repetición en la historia. La experiencia política auténtica está absolutamente libre de esta ilusión"

Walter Benjamin

Ante el embrutecimiento de la conciencia ofuscada en la ratio abstracta, que Horkheimer y Adorno han vinculado a la rebelión de la naturaleza, se opera una fractura que tiene por deriva una subjetividad esquizoide, cuya mirada resulta incapaz de articular el pasado al interior del presente en términos de autocercioramiento, de manera que la experiencia de progreso y la aceleración de los acontecimientos históricos, lo fugaz, así como el que se de una simultaneidad cronológica de evoluciones históricamente asimultáneas le resultan indiscernibles como momentos de un proceso: "Toda reificación es un olvido", dirán Adorno y Horkheimer en la Dialéctica de la Ilustración (Cfr, Adorno, T.W. /Horkehimer, M. 2001, p. 275). No obstante, esta fractura se constituye a contrapelo de la tradición crítica, en la medida en que el ego kantiano ilustrado, si bien aún abstracto, remite a una forma de experiencia reflexiva de lo social y lo político diferida: “ ¿Vivimos 
ahora en una época ilustrada?...no, pero sí en una época de ilustración" (Cfr. Kant, 1784/2004), que supone una liquidación de las entidades trascendentes a las cuales el entendimiento solía recurrir en forma de legitimación, en razón de la cual, correspondería al sujeto moderno la $\sigma \kappa \Upsilon \chi \imath \omega$ de sus objetos de experiencia social, política, práctica y teórica, a partir del diagnóstico crítico en torno a su presente y su reflexión sobre la historia:

"La interpretación de una realidad con la que se tropieza y su superación remiten la una a la otra. Desde luego, la realidad no queda superada en el concepto; pero de la construcción de la figura de lo real se sigue al punto, en todos los casos, la exigencia de su transformación real. El gesto transformador del juego del enigma y no la mera solución como tal, da el prototipo de las soluciones, de las que sólo dispone la praxis materialista. A esa relación la ha denominado el materialismo histórico con un término filosóficamente acreditado: dialéctica”. (Cfr. 1938/1991, Adorno, p. 94).

Una primera aproximación al concepto de imagen dialéctica como $\sigma \kappa \Upsilon \chi \imath \omega$ materialista tiene por requisito previo la determinación del sentido de la crítica, la cual, como advierte Foucault en Qué es la Crítica? (Crítica y AufKlärung) (1978/2004) guarda un nexo indisoluble (en el que se juega incluso la posibilidad misma de la filosofía, y abre el horizonte filosófico para la tradición de pensamiento dialéctico que despliegan los frankfurtianos:

"¿Qué es la crítica?[...]este proyecto que no cesa de formarse, de prolongarse, de renacer en los confines de la filosofía, en sus alrededores, contra ella, a sus expensas, en la dirección de una filosofía por venir, quizás en el lugar de toda filosofía posible. Y me parece que entre la alta empresa kantiana y las pequeñas actividades polémico-profesionales que llevan este nombre de crítica, ha habido en el Occidente moderno (fechado grosera, empíricamente, a partir de los siglos XV-XVI) una cierta manera de pensar, de decir, también de actuar, una cierta relación con lo que existe, con lo que sabemos, con lo que hacemos, una relación con la sociedad, con la cultura, también una relación con los otros, que podríamos llamar la actitud crítica[...] y que sería específica de la civilización moderna..." (pp. 4-5)

\section{(c) (i) (2)}

La Revista Estudios es editada por la Universidad de Costa Rica y se distribuye bajo una Licencia Creative Commons Atribución-NoComercial-CompartirIgual 3.0 Costa Rica. Para más información envíe un mensaje a revistaestudios.eeg@ucr.ac.cr. 
En este sentido resulta perentorio incorporar dentro del campo de la crítica, abierto por el propio filósofo de Königsberg, análisis de la fractura operada y operante sobre la mirada de la subjetividad ilustrada, (cuyo plano inmediato se encuentra ofrecido en Was ist Aufklärung?) su trasfondo y el proceso de sublimación de la naturaleza que se verifica en el ordo de la cultura (Kultur), y para el caso de este breve estudio, el campo de la producción simbólica dentro del que las imágenes adquieren rango de objeto epistémico-político para el pensamiento dialéctico.

La elaboración de la categoría de imagen dialéctica requiere comprender cómo se entiende su vinculación con el propio concepto de dialéctica. En ese sentido, sostiene Adorno respecto de la dialéctica:

"No es de hecho ni sólo método ni tampoco algo real entendido ingenuamente. No es un método: ya que la cosa no reconciliada, y que carece precisamente de esa identidad que el pensamiento imita está llena de contradicciones y se cierra a cualquier tentativa de una interpretación unánime. Pero es la cosa la que da motivo a la dialéctica, y no el impulso organizador del pensamiento. Tampoco es algo simplemente real: puesto que la contradictoriedad es una categoría reflexiva, la confrontación pensante de cosa y concepto" (Adorno, 2001, p. 48).

Una imagen relevante para la dialéctica es aquella que va más allá de sí misma, y ello no es una mera cuestión de contenido o de forma considerados en forma separada, sino que, siendo ella misma una producción simbólica congelada, y ello es manifiesto en el caso de la plástica, se manifiesta como transitoriedad bloqueada y/o como metáfora del cambio en la permanencia aristotélico. En efecto, ante la inmediatez permanecen ocultas en la presencia del fenómeno tanto las relaciones sociales como su lógica interna, y al interior del movimiento, entendido como cambio de un estadio a otro, la cosa misma se expresa a través del cambio en términos de una pérdida de permanencia y la añoranza ideológica del retorno de lo idéntico que emerge con el acabamiento del "buen tiempo", el

\section{(C) $(0 \bigcirc$}

La Revista Estudios es editada por la Universidad de Costa Rica y se distribuye bajo una Licencia Creative Commons Atribución-NoComercial-CompartirIgual 3.0 Costa Rica. Para más información envíe un mensaje a revistaestudios.eeg@ucr.ac.cr. 
cambio resulta mera $\mu \varepsilon \tau \alpha \beta o \lambda \rightarrow$ en sentido antiguo (metábole, término griego que designa el cambio a otro estadio y el cambio meteorológico) abstracta, se ontologiza y se saca del mapa determinaciones que aportarían una mayor concreción del término como trueque, cambio, tráfico o transformación.

Por otro lado, la dialéctica como mirada se constituye en un dispositivo analítico cuya función es la de comprender/desmontar procesos de orden sociohistórico que se ofrecen, en el caso de la imagen como naturaleza. Lo característico de este dispositivo analítico es que articula en forma conflictiva los niveles conceptuales y graficidad (Anschaulichkeit), al interior de una constelación experiencial en cuyos contornos la dialéctica penetra, saturando de concreción su representación filosófica. El pensamiento dialéctico devana el aparecer de la imagen en sus efectualizaciones concretas, tal es la forma de proceder inmanente que reclama el nervio de la dialéctica materialista en el trazado constelar de mediaciones liquidadoras de la permanencia arcaica:

"Al hablar de que la filosofía dispone del material conceptual, no pierdo de vista la estructuración y las formas de agrupación del material de la investigación, la construcción y la creación de constelaciones. Pues las imágenes históricas, que no forman el sentido de la existencia, pero resuelven y disuelven sus cuestiones, no son meramente algo dado por sí mismo. No se encuentran listas ya en la historia como preparados orgánicos; no es preciso descubrir visión ni intuición alguna al respecto, no son mágicas divinidades de la historia que habría que aceptar y honrar. Antes bien, han de ser producidas por el hombre y sólo se justifican al demoler la realidad en torno suyo con una evidencia fulminante. En esto se diferencian radicalmente de los arquetipos arcaicos, míticos, que encuentra el psicoanálisis, y que Klages espera poder preservar como categorías de nuestro conocimiento". (Adorno, 1991, pp. 98-99).

La inmersión dialéctica en la imagen (des)identifica la historia, mostrando su no identidad en tanto que proceso, que, sólo en una recuperación abstracta, lo 
cual compromete la idea de proceso salvo que se restrinja en forma equívoca a una sucesión líneal de eventos, sirve a la fetichización afirmativa de lo dado. De ahí que, aunque sea común la pretensión de ecuación (como la que en su momento de gloria la caverna del neoconservadurismo postmoderno, proyectó sobre el materialismo histórico, de la mano de Popper), la categoría dialéctica de proceso no es lo mismo que una procesión.

En efecto tal diferenciación ha sido anticipada por el propio Hegel, en el orden del concepto:

"La idea es esencialmente proceso porque su identidad es la identidad absoluta y libre del concepto sólo en tanto es absoluta negatividad y por ende dialéctica. Es el transcurso [que consiste en] que el concepto en tanto universalidad que es singularidad, se determina a la objetividad y a la oposición frente a sí misma, y esta exterioridad que el concepto tiene como sustancia suya se reconduce a la subjetividad por su dialéctica inmanente". (Hegel, G.W.F. 2000, p. 215)

La determinación concreta del objeto sociohistórico es expresado en su lenguaje particular en el momento en que la mirada actualiza, por medio de las categorías dialécticas, la recuperación de la lógica conflictiva que constituye la experiencia estética de carácter enfático, como señaló Adorno. Capricho No. 43 de Francisco de Goya (1746-1828), intitulado: "El sueño de la razón produce monstruos" (1799), producido al interior de una formación económico-social aún retardataria en/desde la Europa ilustrada ofrece condensada en el orden visual la experiencia tensa cuya génesis es de particular interés para la skepsis materialista:

"Esta pesadilla, pone en evidencia un mundo atroz, que en la época de Goya se vivía no en sueños sino en la realidad. En las circunstancias de una España sumida en el caos de la guerra y que vivía bajo el peso de una Religión medievalista que practicaba los castigos de la inquisición; de esta manera, España estaba regida por una especie de superstición medieval, 
por una especie de ignorancia, en la que se hacía evidente la ausencia de la Razón. Por otra parte, Goya, fue un hombre que vio cómo su país estaba gobernado por el caos, por la corrupción de sus gobernantes y por los "Desastres de la guerra", título de otra serie de grabados. Con esta obra, de "Ios sueños de la razón", Goya quería hacer un llamado o un señalamiento, a la situación de España en el s. XVIII que estaba "dormida" o de espaldas a la Razón. Este grabado tenía inicialmente un prefacio que fue abolido cuando se publicó la obra: "Para el artista que sueña su único objetivo es eliminar creencias perjudiciales y vulgares, y perpetuar, en esta obra de caprichos, el testimonio de verdades sólidas”. (Rodríguez, 2010).

\section{(c) (i) (2)}

La Revista Estudios es editada por la Universidad de Costa Rica y se distribuye bajo una Licencia Creative Commons Atribución-NoComercial-CompartirIgual 3.0 Costa Rica. Para más información envíe un mensaje a revistaestudios.eeg@ucr.ac.cr. 


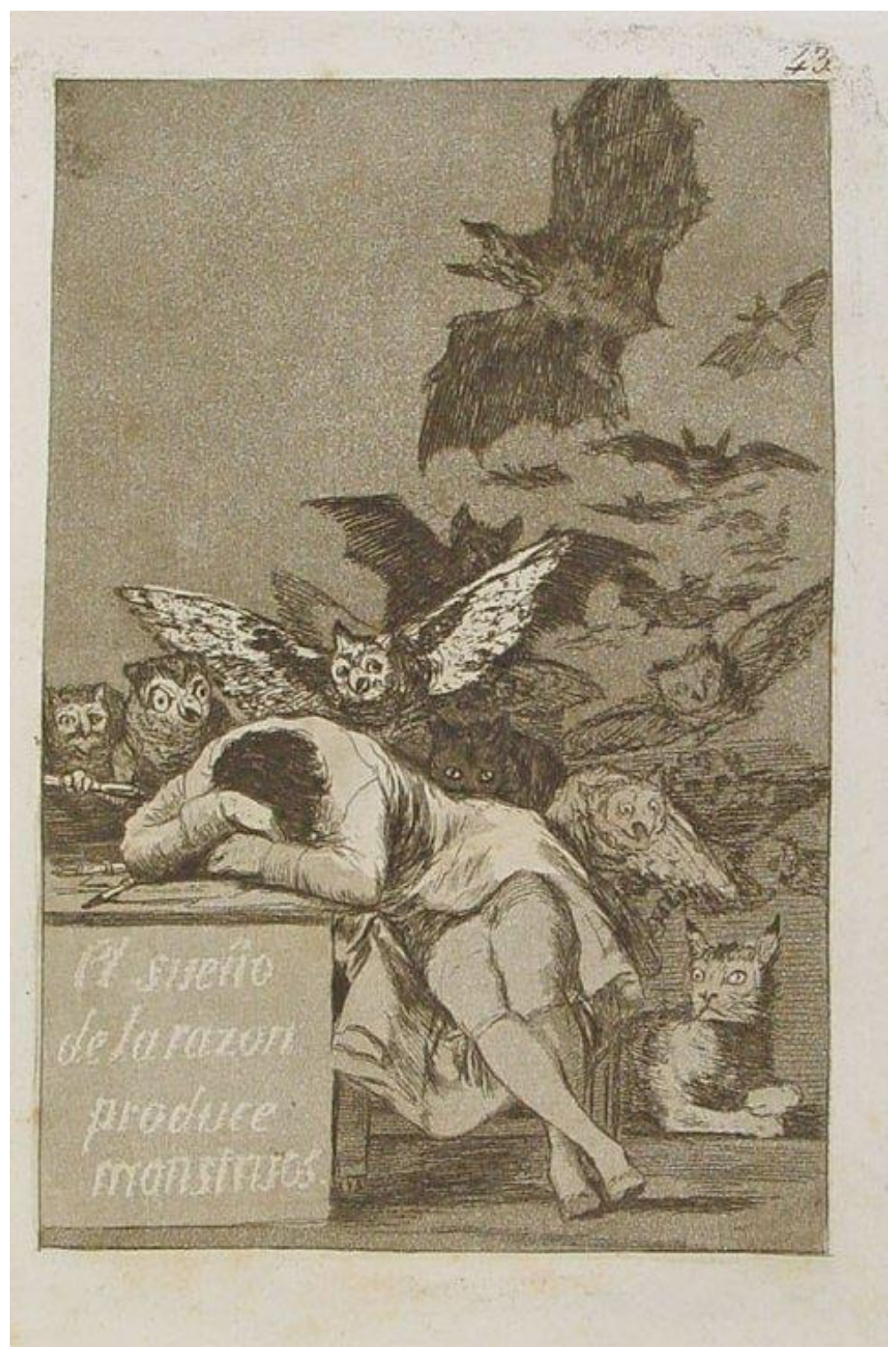

Goya, 1799. El sueño de la razón produce monstruos. Recuperado de http://es.wikipedia.org/wiki/Archivo:El sueño de la razón prod uce monstruos.jpg el 14 de Mayo del 2010 a las 20:00 horas.

Dialéctıcamente, este caprıcho de Gioya otrece una suerte de elaboración alegórica muy rica y plena de imágenes metafóricas: el autor que duerme, un gato negro en su espalda, búhos y otro gato más claro, cuyos ojos parecen "activarse" y alzar vuelo en el momento en que constatan la condición del autor y más arriba,

\section{(a) $(\oplus \Theta$}

La Revista Estudios es editada por la Universidad de Costa Rica y se distribuye bajo una Licencia Creative Commons Atribución-NoComercial-CompartirIgual 3.0 Costa Rica. Para más información envíe un mensaje a revistaestudios.eeg@ucr.ac.cr. 
al tiempo que se efectualiza el arribo de una pluralidad oscura de chiroptera, tanto por su coloración como por su cantidad que se pierde en el Capricho. E despliegue cromático de este Capricho es también dialécticamente relevante en la medida en que posiciona hacia el frente la iluminación-dormida del autor, iluminación dormida y evanescente en el vuelo de los búhos, que como el búho de Minerva con que en Hegel expresa la manifestación de la filosofía, que alza el vuelo al caer de la tarde, siendo que la lucidez del espíritu que verte en conceptos los hechos de la historia trabaja en medio de la noche del mundo. Ya ese posicionamiento del autor dormido arroja luz sobre la producción de sentido que

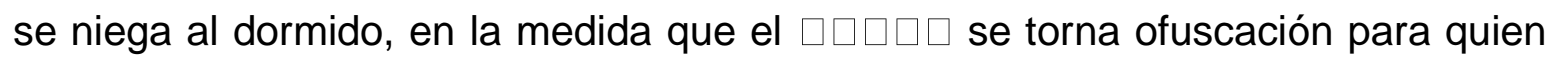
aún despierto opera como si estuviese dormido, como sabía el viejo Heráclito:

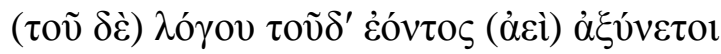

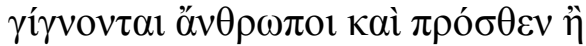

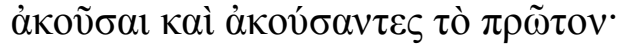

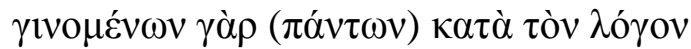

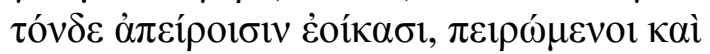

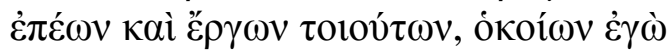

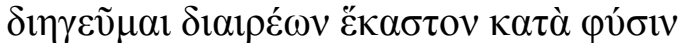

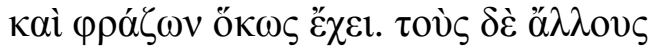

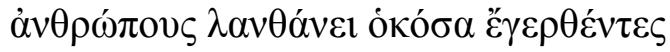
$\pi 010 \tilde{\sigma \imath v, ~ o ̋ \kappa \omega \sigma \pi \varepsilon \rho ~ o ́ \kappa o ́ \sigma \alpha ~ \varepsilon v ँ \delta o v \tau \varepsilon \varsigma ~}$ $\dot{\varepsilon} \pi \imath \lambda \alpha v \theta \alpha ́ v 0 v \tau \alpha 1$.

La traducción al castellano de este fragmento, tal como la ha vertido Rodolfo Mondolfo (1973, p.30), es la siguiente:

"Aun siendo este logos real, siempre se muestran los hombres incapaces de comprenderlo, antes de haberlo oído y después de haberlo oído por primera vez. Pues a pesar de que todo sucede conforme a este logos, ellos se asemejan a carentes de experiencia, al experimentar palabras y acciones como las que yo expongo, distinguiendo cada cosa de acuerdo con su naturaleza y explicando cómo está. En cambio, a los demás hombres se les escapa cuanto hacen despiertos, al igual que olvidan cuanto hacen dormidos". (de SEXT., Adv. Math., VII, 132).

\section{(c) (i) (2)}

La Revista Estudios es editada por la Universidad de Costa Rica y se distribuye bajo una Licencia Creative Commons Atribución-NoComercial-CompartirIgual 3.0 Costa Rica. Para más información envíe un mensaje a revistaestudios.eeg@ucr.ac.cr. 
Una lectura no dialéctica de "El sueño de la razón produce monstruos" tiende a considerar "el sueño" en yuxtaposición a "los monstruos" en una expresión paradójica, porque siendo su espíritu eminentemente romántico, su procedimiento es enteramente mecánico. En este procedimiento que podríamos denominar romántico-mecànico se condena la forma privilegiada de experiencia epistémico-política de la modernidad que para los teóricos de la llustración se identificó con "la" Razón en tanto que programa, por lo que mejor sería una suerte de retorno que asegure un imaginario que o bien permanezca plácidamente retardatario, añorando lo pasado en un vínculo orgánico con la naturaleza , que bien puede coexistir con uno en el que progreso y el orden contra las derivas negativas (críticas) de la llustración entendida como proyecto civilizatorio. Estas derivas negativas (revolucionarias) dentro de tal imaginario reaccionario serían lo que habría que frenar y reprimir para asegurar la paz social. En este imaginario los sueños de la Razón son teratologizados para asegurar el predominio del miedo, la superstición y la ideología que basamenta y reproduce la lógica de dominio. Acá, en esta lectura no dialéctica, coincide la aparente contradictoriedad de romanticismo y positivismo (cuya expresión paroxísistica conduce a religión tecniárquica). Entonces el juicio mecánico que tuvo fortuna en el momento en el que la caverna posmoderna celebraba el fin de la historia y "la" modernidad (cualquier cosa que eso quiera significar) es el siguiente: La razón es totalitaria, es terrorífica, binaria, falogocéntrica y toda una serie de teratologizaciones tendientes a legitimar un "pensamiento débil" en términos de Vattimo, al tiempo que desde una estetización de la política (procedimiento caro al nazismo, que dicho sea de paso yuxtaponía en su retórica elementos romantizantes procedentes del volkisch y el culto de la máquina) terminaban sancionando las tramas de dominación estructural al interior del capitalismo tardío. En lugar de producir un mito denominado "Razón" para justificar la inacción política, la comprensión dialéctica de "El sueño de la razón produce monstruos, desmonta tal construcción unilateral, reconduciendo "el sueño" a la noción de experiencia, y particularmente, el principio 
de contradictorio como index de inteligibilidad. La mirada dialéctica desmonta la ilusión metafísica que fetichiza los fenómenos, como bien sabe Adorno (1986):

"Las categorías de la crítica al sistema son a la vez las que comprenden lo particular. Aquello que en el sistema ha llegado legítimamente a superar lo singular, tiene su lugar fuera del sistema. La mirada que seculariza la metafísica es la que al interpretar el fenómeno descubre lo que es, gracias a que percibe en él más de lo que meramente es" (p. 36).

Dialécticamente la experiencia del sueño sólo se comprende de cara a su opuesto, y con relación al sujeto epistémico: dormido-despierto, donde el sentido de lo real y la experiencia histórica como proceso conflictivo hacen sintagma. La disposición del color incardinada en las imágenes metafóricas citadas arriba, los búhos siempre relativos a la actividad filosófica, los gatos que remiten a la enigmática experiencia de lo oculto y los chiroptera que arriban tras la batida en retirada de los primeros. Es el momento de tensión en la noche y el día de la vida, como señalaría Hegel, donde se vuelve absolutamente crucial y enfático (dirá Adorno) mantenerse despierto. El autor, en este sentido, al dormir sufre la recaída en la inmediatez, la brutal venganza de la naturaleza y se torna el protagonista inerme del mito:

"Los mitos dan respuesta a por qué el mundo es como es, cuando una relación empírica de causa -efecto no puede ser vista, o cuando no puede ser recordada. Aunque satisfacen el deseo de los seres humanos por un mundo pleno de sentido, lo hacen al precio de devolverles ese mundo bajo la forma de un destino inescapable. Tanto la ciencia como la teología, el racionalismo o la superstición pueden pretender que los acontecimientos están inexorablemente determinados. Tampoco las explicaciones míticas se restringen a una época particular. Tienen su fuente (occidental) en la antigüedad y en la narrativa bíblica. Pero reaparecen en las especulaciones cosmológicas más recientes, por ejemplo, en la interpretación del holocausto nuclear como cumplimiento de la profecía bíblica -un intento perverso, desde la perspectiva crítica de la "historia", de asignarle a Dios la responsabilidad por la aterradora situación que los mismo seres humanos han creado". (Cfr. Buck-Morss, 1995, p.95). 
La interpelación dialéctica que opera este Capricho, no obstante, y desde el universo categorial de la dialéctica, resulta oscura para el dormido, lo cual da cuenta de la situación que se configura en la actual noche del mundo, en donde la interpretación que ha prosperado y ha sido difundida con mayor insistencia haya sido la del despierto que actúa como dormido, aquella que construye una teoría mítica de la Razón (como programa perverso) y la historia (como realización de los monstruos que emergen de aquella): la mirada fetichizada de este documento de cultura/barbarie que le instrumenta en forma afirmativa.

Al igual que en el caso del autor de Los desastres de la guerra (1810-1814), cuya denuncia de la irracionalidad por medios visuales se produce dentro del contexto de la guerra de la independencia librada por España contra la invasión francesa, la imagen dialéctica tiene otra de sus expresiones más poderosas, esta vez una Alemania atravesada por los horrores de la guerra total al interior de una formación económico-social cuya organización de la existencia que continúa, tras la guerra, destruyendo estructuralmente cuerpos y que actualiza la advertencia de Max Horkheimer, en Die Juden und Europa (Cfr. Bauer et Al. 1967, p. 9: ): "Sin embargo, el que no quiera hablar del capitalismo, que calle también en lo tocante al fascismo".

En 1923 Félix Hartlaub, quien en ese momento fungía como director de la Kunstshalle, Mannheim, acuña el nombre con el que será identificada la tercera deriva del Expresionismo Alemán: la Neue Sachlichkeit, la Nueva Objetividad. Su producción estética (lo mismo que Goya, siendo ubicado como romántico en la historia del arte, resulta dialécticamente afín al proyecto civilizatorio ilustrado una España durmiente a espaldas de la razón) trae a la graficidad la confrontación y el conflicto contra la centralización y el fortalecimiento del poder estatal que anuncia el ascenso del irracionalismo nazi en la política. La exposición de la Neue 
Sachlichkeit realizada en 1923, en Berlín, agrupaba la obra de artistas como Georg Scholz, Max Beckham, Otto Dix y Georg Grosz, quienes habían comprendido que la bandera del arte por el arte, era insostenible en tal orden de cosas no sólo por reaccionaria e ingenua sino que la idea de la neutralidad del arte terminaría, por un lado en una forma estetizante de eludir el conflicto social, y, por otro, en una manifestación justificatoria del arte al servicio del nazismo. En ese sentido, los objetivos críticos de la Neue Sachlichkeit serán la crítica de lo cotidiano, de la banalidad y la dinámica socio-política de la Alemania de entreguerras.

Para 1933 las obras del grupo estarían en la mira de los nazis que organizaron la confiscación y quema en piras espectaculares para su destrucción, y en 1937, como producto de la confiscación serían presentadas en Monaco en una exposición denominada Entartete Kunst (arte degenerado), dentro de la cual se ubicaban, además de Dix, Grosz, Bekcham y Scholz, en la plástica y la escultura, Paul Klee, Erich Heckel, Ernst Ludwig Kirschner, Oskar Kokoschka, Rolf Kurth; en músicos como Bartok, Hanns Eisler, Paul Hindemith, Ernst Krenek, Kurt Weil y Arnold Schönberg; escritores como Franz Kafka, Bertold Brecht, Thomas Mann, Heinrich Mann; lo mismo que directores y actores como Fritz Lang, Kurt Gerron y Peter Lorre. (Cfr. http://www.kassiber.de/entartete-kunst/). 
Revista Estudios, (37), 2018.

Diciembre 2018-Mayo 2019

ISSN 1659-3316 Fallas Vargas Fabrizio

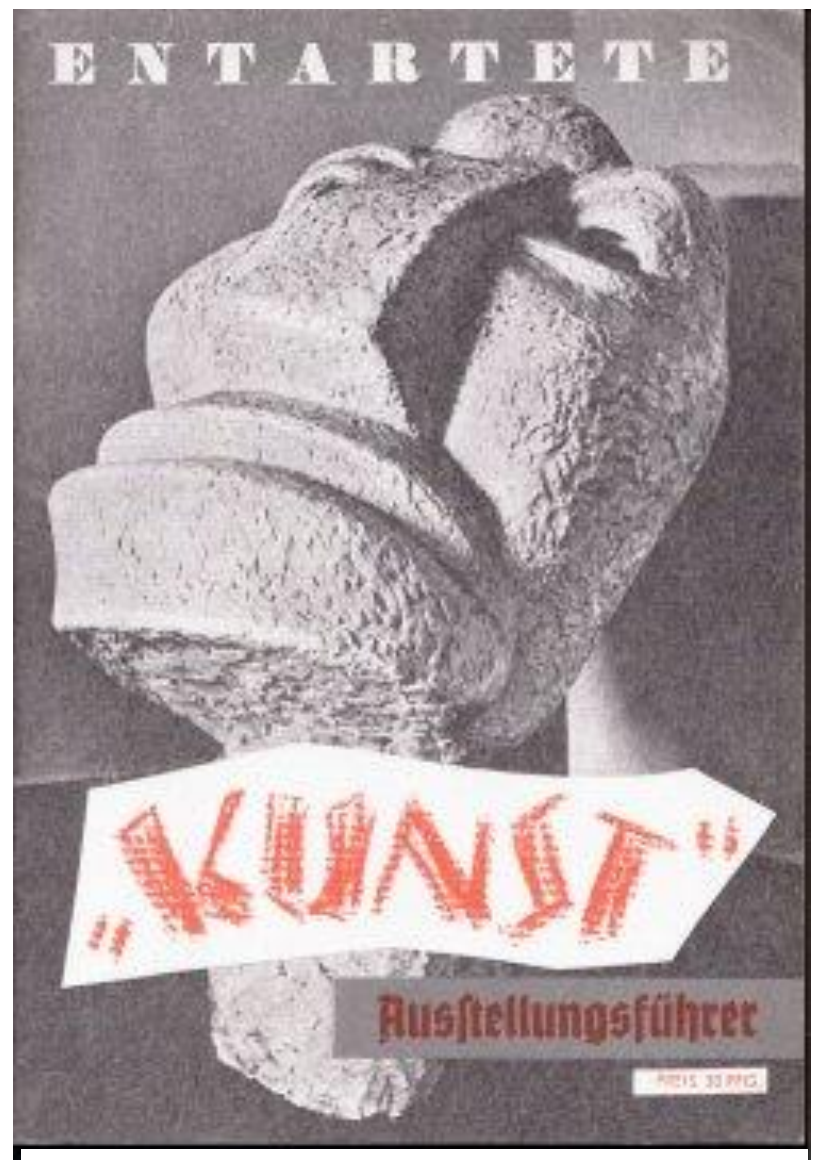

Portada del catálogo de la exposición de "Arte degenerado", $1937 . \quad$ Extraída de http://www.kassiber.de/entartete-kunst/), 25 de Junio del 2010.

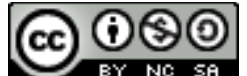

La Revista Estudios es editada por la Universidad de Costa Rica y se distribuye bajo una Licencia Creative Commons Atribución-NoComercial-CompartirIgual 3.0 Costa Rica. Para más información envíe un mensaje a revistaestudios.eeg@ucr.ac.cr. 


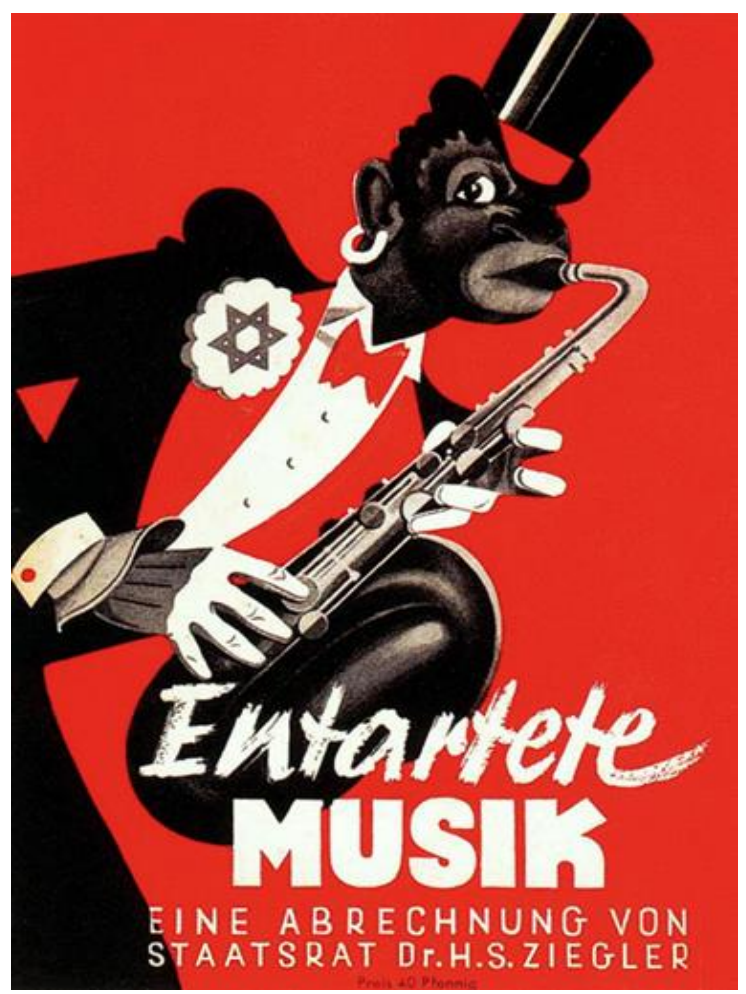

Poster oficial, cargado de connotaciones racistas. Muestra de música degenerada, 1938. Extraído

de http://www.austrianinformation.org/november -december-2005/2007/2/14/915452.html, 25 de junio del 2010.

La producción de Georg Grosz (1893-1959), al interior de la Neue Sachlichkeit, es de particular relevancia en este estudio, en la medida en que su imagen dialéctica restituye en una crítica de su tiempo, el logos conflictivo que actualiza la negatividad/racionalidad obturadas en/desde los lugares sociales que proveen la materialidad de lo cotidiano y, en línea con la tradición crítica ilustrada, cara a la dialéctica, se enfrenta en forma explícita con la hipostatización de lo dado. En Grosz, tal tradición converge con la dialéctica materialista, en la medida que la mirada, se sabe construida, pero al tiempo, se inserta dentro de la dinámica de lo político en la configuración de espacios epistémicos o bien funcionando a expensas de la imaginería dominante. En la filosofía alemana moderna, desde

\section{(C) $(\Theta \odot \odot$}

La Revista Estudios es editada por la Universidad de Costa Rica y se distribuye bajo una Licencia Creative Commons Atribución-NoComercial-CompartirIgual 3.0 Costa Rica. Para más información envíe un mensaje a revistaestudios.eeg@ucr.ac.cr. 
Kant, la epistemología se dobla en filosofía política, y el artista, en tanto que productor simbólico enfrenta dentro del conflicto social, la lucha por el sentido, que, en el caso de Grosz, pasa por la decidida toma de posición por un proyecto civilizatorio alternativo a la organización de la existencia capitalista y que identifica la tarea del artista revolucionario en sus componentes práxicos (estos no se entienden en el sentido vulgar como mera movilización política) sino en la capacidad de elaborar por medio de la imagen espacios epistémicos de carácter negativo. En ese sentido, Muñoz ha advertido el vínculo de la imagen grosziana con la emergencia del dodecafonismo en la antesala de la catástrofe:

"La configuración del movimiento dodecafonista corre paralelo con la formación de una sociología crítica que se enfrenta a la decadencia de la sociedad europea tras el Tratado de Versalles. Decadencia que va sedimentando una nueva sensibilidad y subjetividad artísticas que asumen con clarividencia su responsabilidad ante la llegada inminente de la catástrofe. La música deja de ser un arte inofensivo y se hace expresión de los procesos sociales. Será precisamente la ópera dodecafónica la que plasme el sufrimiento del sujeto con la dolorosa intensidad de quienes prematuramente se asoman al cataclismo bélico. $Y$ si en pintura será Grosz quien retrate la incongruencia social de un deteriorado Berlín, en música van a ser las óperas de Berg y de Schönberg, en una cosmopolita Viena, las que dejen oír los subterráneos de una sociedad que se encamina a la destrucción" (Cfr. 1998, p. 261).

En Grosz, esta generación de espacios epistémicos negativos pasa por una experiencia estética que remite explícitamente a una mirada cuya agudeza materialista elabora un vínculo con su objeto específico. En palabras de Grosz, ello requiere un esfuerzo de agudización del visionar intra/intersubjetivo, eso es, en la relación real del sujeto con el entorno concreto, a sabiendas de que se trata, ante todo de una empresa orientada contra las pretensiones de un arte virginal y desvinculado del conflicto social:

\section{(c) (i) (2)}

La Revista Estudios es editada por la Universidad de Costa Rica y se distribuye bajo una Licencia Creative Commons Atribución-NoComercial-CompartirIgual 3.0 Costa Rica. Para más información envíe un mensaje a revistaestudios.eeg@ucr.ac.cr. 
"Es un error creer que si uno pinta círculos, cubos o marañas de profundo significado espiritual, es -acaso e contraste con Makart- un revolucionario. Contemplad a Makart: es un pintor de la burguesía, pinta las ansiedades, los contenidos y la historia de esta. ¿Y vosotros? ¿Qué sois vosotros, sino miserables acólitos de la burguesía?[...]Pretendéis ser atemporales y hallaros por encima de los partidos -oh guardianes de la 'torre de marfil' que hay en cada uno de vosotros-, pretendéis crear para el hombre, ¿pero dónde está este hombre? ¿Qué son vuestra indiferencia creadora y vuestras abstractas necedades de atemporalidad, sino una ridícula e inútil especulación sobre la eternidad? Vuestros pinceles y plumas, que en nuestras manos deberían ser como armas, no son más que cañas vacías de contenido". (Cfr. Grosz, 1925/1977, p. 22).

En ese sentido uno de los rasgos característicos de la imagen dialéctica grosziana reside en el desmontaje del continuum de lo cotidiano festivo y el restablecimiento del vínculo con su lógica subterránea y material. La liquidación de la racionalización, en sentido psicoanalítico, que cubre con el manto de la imagen afirmativa la realidad de la barbarie instalada en el statu quo. La imagen grosziana se constituye en propia arma de la racionalidad en la graficidad y en tal medida coincide con la crítica implacable de las tendencias retardatarias que operan a espaldas de la concreción de la razón, como el trazo de Goya había anunciado en su capricho No. 43. Una amplificación de la mirada materialista de lo cotidiano traslada al sujeto de lo festivo inmediato a la catástrofe visual, y, el movimiento de la dialéctica contenida en el arribo de los monstruos de Goya, cristaliza en sus expresiones institucionales. Los Pilares de la Sociedad, de 1926, expresa por medio de elementos alegóricos su potencia negativa.

\section{(c) (†) (-)




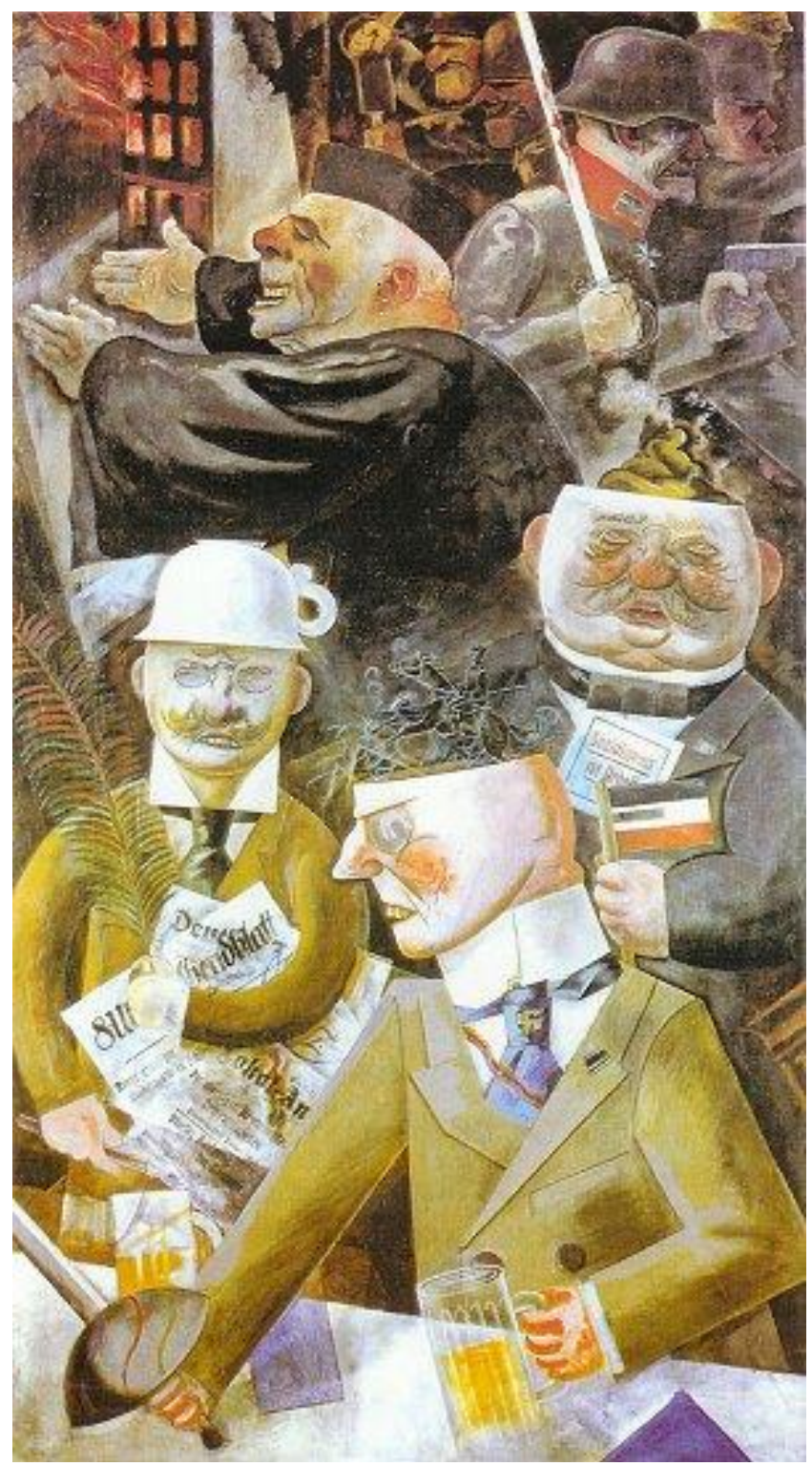

Georg Grosz, Los pilares de la sociedad, 1926. Extraído de http://clubhausia.fsrvv.de/?Zeitdokumente:Bilder,

20 de Junio del 2010.

Homónima de la obra de teatro de lbsen (1877) en la que la burguesía victoriana se ve enfrentada con sus propias contradicciones en el momento en que el mundo y el aparato simbólico que ha construido (atravesado materialmente por el prejuicio y la hipocresía), y dentro del cual la idea de libertad hacía sintagma con el autocercioramiento (que en Ibsen funcionaría como correctivo ético), se

\section{(C) $(\Theta \odot \odot$}

La Revista Estudios es editada por la Universidad de Costa Rica y se distribuye bajo una Licencia Creative Commons Atribución-NoComercial-CompartirIgual 3.0 Costa Rica. Para más información envíe un mensaje a revistaestudios.eeg@ucr.ac.cr. 
encuentra, como diría Marx, putrefacto, Los pilares de la sociedad de Grosz (tema que también será retomado en la década de los treinta por John Heartfield y Oskar Nerlinger), iluminan fragmentos la alegoría de una totalidad social que condensa las patologías de la Alemania de la postguerra, en donde la pluralidad cromática es fundamental. Los pilares de la sociedad develan estas patologías sociales por medio del concreto aparecer de figuras que se despliegan en una "cascada" ascendente, en donde el primero antecede en plano de aparición al que le sucede y así sucesivamente, desde el nazi que empuña la espada hasta los soldados que empuñan granadas en la trinchera, o si se quiere en orden descendente, lo cual requeriría un mayor esfuerzo por parte del sujeto al que la imagen interpela, dada la disposición de planos en que cada figura aparece y según la cual en la parte superior del cuadro, las figuras adquieren colores menos luminosos y ocupan un espacio mucho más reducido, respecto de las que se aprecian cercanas a una altura menor en el espacio del cuadro. Cuanto menor la altura en la que se dispone la figura, mayor visibilidad imprime Grosz.

La disposición de estas figuras no es gratuita, sino que dialectiza la lógica endogrupal y la carga libidinal de la autoridad que comparten en Adorno la inversión psicoanalítica en la industria cultural y la propaganda fascista:

"Incluso los asombrosos síntomas de inferioridad del líder fascista, su parecido con los actores histriónicos y los psicópatas asociales, está así anticipado en la teoría de Freud. En virtud de esas partes de la libido narcisista del adepto que no se han señalado en la imagen del líder, sino que permanecen adheridas al propio ego del adepto, el superhombre tiene que seguir pareciéndose al adepto y aparecer como su ampliación[...]la imagen del líder fascista gratifica el deseo doble del adepto de someterse a la autoridad y de ser la autoridad él mismo. Esto se adecua a un mundo en el que se ejerce el control irracional, aunque ha perdido su convicción interna debido a la ilustración universal. La gente que obedece a los dictadores percibe también que los últimos son superfluos. Esta gente reconcilia la contradicción asumiendo que ellos mismo son el opresor implacable". (Cfr. Adorno, 1951/2004, pp. 293-294). 
Las marcas identificatorias del adepto aparecen en el primer plano en el que se ha incrustado un sujeto con monóculo, una cicatriz (ha de recordarse que en este contexto una cicatriz evidencia fundamentalmente la participación en algún duelo en orden a la defensa de la virilidad y el honor, lo cual es reforzado en el instante en que el sujeto del primer plano blande una espada o incluso la participación en la I Guerra Mundial), la esvástica en la corbata, el saco marrón (que emula el color de las Sturmabteilung "SA", o tropas de asalto que sería oficializado en 1926, luego de ser comprados por las SA y el partido Nazi remanentes de uniformes en este color que quedaron de la I Guerra Mundial y cuyo destino era el ser utilizado por las tropas en África), con una espada en la mano derecha (con cintas de colores primarios que podrían aludir a una crítica desde la Neue Sachlichkeit a la estética fauvista-futurista de tintes místico teosóficos en la pesquisa de un presunto arte puro despojado de particularidad, en el caso de Mondrian (1872- 1944) que tendrán fortuna en el diseño industrial y la publicidad sigloveintista) y una cerveza en la izquierda, tiene su cráneo abierto que cumple su función en el momento en que de su oquedad emerge un caballito de batalla que asciende en el espacio del cuadro, al tiempo que el adepto se concentra, mostrando sus dientes con furia y con su mirada hacia abajo, en la espada que extiende/arma su brazo derecho.

Siguiendo el orden ascendente de los planos en que se articulan las figuras en Los pilares de la sociedad, a la derecha del adepto (desde la perspectiva que tendría el adepto en su ubicación espacial) aparece Alfred Hugenberg (18651951), fundador de empresas de comunicación, prensa e industria cinematográfica, quien tras la derrota de Alemania en la I Guerra Mundial (siendo miembro de la Asamblea Constituyente y del Reichstag hasta la disolución de la República de Weimar), lideró el Partido Nacional Popular Alemán, aprobó la cancillería de Hitler, integrándose posteriormente al régimen como ministro de Economía y Agricultura. Hugenberg luce en su mano izquierda (asumiendo, como 
se señaló antes posición anatómica) una pluma de gran tamaño, con áreas coloreadas en rojo (la tinta roja que mancha la estructura de esta pluma bien haría referencia a la sangre que alimenta el orden del régimen) protegiendo con el área de sus costillas una serie de propaganda escrita y periódicos de los cuales baja, claramente un rastro de sangre; su brazo derecho sostiene un objeto alargado que semeja un lápiz color rojo sanguinolento. La expresión del rostro es confrontativa y tiene el ceño fruncido. Al igual que el adepto muestra sus dientes, y, vistiendo el color marrón del partido, tiene por tapadera de su presumible oquedad craneal una bacinilla. Ello indica bien que el propio empresario de los medios es de por sí un gran excremento y bastaría invertir su posición, o bien, que, a diferencia de la figura que le sucede, tiene medios para ocultar la visibilidad del contenido escatológico que excreta su cabeza.

La figura relativamente paralela a la de Hugenberg, aunque ocupa un plano posterior, remite a un funcionario de "mayor" rango: Friedrich Ebert, miembro del Partido Socialdemócrata, electo presidente por la Asamblea Nacional en Weimar, tras haber allanado el camino, mediante el pacto Ebert-Groener, para la represión violenta de la Revolución Alemana de 1918-1919. Será objeto de desprecio, obviamente desde la izquierda e incluso dentro del propio PSD, (siendo que desde su curul parlamentaria en la preguerra se había opuesto sólo verbalmente a la guerra, dando voto afirmativo a sus empréstitos), pero también por parte de la Derecha al encabezar, el gobierno provisional que firma el Tratado de Versalles con posterioridad a la derrota del imperio alemán en 1918. Carga en su mano derecha una bandera con los colores del imperio alemán (rojo-blanco) y un cartel con el eslogan demagógico: "Socialismo es trabajo", eso sí, sin huelgas ni revolución, que recuerda la función objetiva que cumplió en la antesala de la catástrofe, la contención del potencial revolucionario y la neutralización de la movilización social de los trabajadores por parte del PSD. El cuerpo regordete del funcionario, que viste un traje negro, y broche en la solapa que bien podría ser el 
ISSN 1659-3316

Fallas Vargas Fabrizio

emblema de la república de Weimar (recuérdese que formalmente pertenece a otro partido), se inclina hacia la derecha con su las mejillas y nariz enrojecidas, boca entreabierta, la mirada perdida (y ello muestra la relevancia política de la disposición espacial-gestual para la imagen grosziana), que se funde en un rostro inexpresivo, mientras de su cavidad craneal exhibe en disposición ascendente una generosa cantidad de excrementos.

El siguiente plano de ascenso en la mirada de la imagen plasmada en la obra presenta un clérigo, cuya fisonomía recuerda al cardenal católico Faulhaber (quien solía acompañar los desfiles de las SA) en una postura edificante, mostrando sus dientes en medio de la prédica. De contextura endomórfica, obeso (nótese la prominente bola de grasa que sobresale de la nuca), sus brazos extendidos dibujan el ademán de la oratoria demagógica en manos paralelas y parecen insertarse en un plano celeste que cubre parcialmente un edificio en llamas. En este caso el contenido de su cavidad craneal es imperceptible dado el tocado negro que completa su indumentaria religiosa, no obstante, es importante visualizar el modo en el que cierra sus ojos al tiempo que verbaliza. Legitimación mistificatoria y la ceguera autoinducida del genocidio por medio de "la palabra" completan la función social de la institucionalidad religiosa al interior del régimen.

Tras la figura clerical, el plano siguiente muestra una serie de miembros de la Reichswehr colocados en la misma línea de Ebert, sólo que a diferencia de este, que es un burócrata traidor (para la izquierda y la derecha) en su desplazamiento muestran la energía necesaria para el desempeño en el combate. El miembro de la Reichswehr que destaca en primer plano sujeta en su mano derecha la espada ensangrentada, la cruz de hierro en su cuello y en la mano derecha una pistola. Tiene un rictus en su boca, sus dientes sobresalen y los músculos de la cara están completamente tensados. El plano que yace en la parte superior, y más atrás, bien remite a las asociaciones de veteranos de la derecha (nótese la notoria edad avanzada de los sujetos, especialmente hacia el área 
superior izquierda del cuadro, arriba del clérigo, con una granada en su mano derecha) nacionalistas afines al régimen como es el caso de la Stalhelm y la Wehrwolf.

Cada uno de estos planos ofrecidos en cascada ascendente por Grosz es suceptible de ser comprendido en forma descendente. Ello es un interesante rasgo de esta imagen dialéctica, hacia arriba y hacia abajo como parte de un mismo proceso que se expresa en forma diferenciada, según el ordo de la investigación y según el orden de la exposición. En ese caso cada uno de los planos posee su propia dinámica interna, que expresa en forma contracta la dinámica concreta (en donde cada figura se encuentra articulada con la otra) de una lógica ético-política (jerarquías monolíticas) que ya aparece de manera germinal en la imagen del folklore alemán de los Radfahrernaturen (caracteres del ciclista), y que como advierte Adorno, presenta rasgos psicoanalíticos de altísimo valor para la dialéctica negativa:

"Freud ofrece una exposición exhaustiva del elemento jerárquico dentro de los grupos irracionales. 'Es obvio que un soldado toma a su superior, esto es, realmente al líder del ejército como su ideal, mientras que él se identifica a sí mismo con sus iguales, y deriva de esta comunidad de sus egos las obligaciones de darse ayuda mutua y de compartir los bienes que implica la camaradería. Pero se convierte en ridículo si intenta identificarse a sí mismo con el general', a saber, consciente y directamente. Los fascistas, hasta llegar al último demagogo de poca monta, enfatizan de forma continua las ceremonias rituales y las diferenciaciones jerárquicas. Cuanto menos jerarquía está garantizada dentro de la organización de una sociedad industrial altamente racionalizada y cuantificada, más jerarquías artificiales se constituyen sin raison d'être objetiva y son impuestas rígidamente por los fascistas por razones puramente psicotécnicas. Puede añadirse, no obstante que esta no es la única fuente libidinosa implicada. Así, las estructuras jerárquicas se hallan en completa consonancia con los deseos de carácter sadomasoquista. La famosa fórmula de Hitler, Verantwortung nach oven, Autorität nach unten (responsabilidad hacia arriba, autoridad hacia abajo) racionaliza amablemente esta ambivalencia de carácter". (Adorno, Ibid. Pp. 393- 394).

\footnotetext{
(C) $(\Theta \circ$

La Revista Estudios es editada por la Universidad de Costa Rica y se distribuye bajo una Licencia Creative Commons Atribución-NoComercial-CompartirIgual 3.0 Costa Rica. Para más información envíe un mensaje a revistaestudios.eeg@ucr.ac.cr.
} 
El depliegue ético político de la ratio identificatoria que se expresa en la imagen grosziana abre al horizonte de la dialéctica el contradictorio benjaminiano, en el que la mirada materialista de la historia pone en tela de juicio la idea del progreso, ya advertida, de acuerdo con el análisis adorniano, por Freud:

"Esta tendencia a pisar a los de abajo, que se manifiesta ella misma de forma tan desastrosa en la persecución de minorías débiles y desprotegidas, es tan evidente como el odio contra los de fuera. En la práctica ambas tendencias se dan juntas con bastante frecuencia[...]En toda nuestra cultura este modo de pensar y comportarse ha llegado a ser considerado como autoevidente, hasta tal grado que la cuestión de por qué la gente ama lo que se parece a ellos y odia lo que es diferente, rara vez se plantea con suficiente seriedad[...]Ya en 1921 era capaz por ello de suministrar la ilusión liberal de que el progreso de la civilización produciría automáticamente un incremento de la tolerancia y una disminución de la violencia contra los grupos externos". (Ibid. P.394).

El contradictorio, constitutivo de la lógica dialéctica, desde Heráclito, es desarrollado con la mayor concreción en el concepto benjaminiano de imagen dialéctica como dispositivo de análisis materialista de la historia. Hacia 1940, año en que decide acabar con su vida antes de ser capturado por agentes de la Gestapo destacados en la frontera franco-española, Benjamin formula sus Tesis sobre Filosofía de la historia, al interior de las cuales la interpenetración de las imágenes dialécticas y el orden conceptual se manifiesta en forma única. La tesis IX interesa en este estudio en la medida en que tal interpenetración tiene una obra del Paul Klee, de 1920: Angelus Novus, cuyo carácter icónico para la izquierda y particularmente pensadores dialécticos es indidudable, al punto que su propia historia de vida daría material para capturar la experiencia histórica como ruptura de un continuum y la exigencia de pensar la irrupción obligatoria de lo nuevo:

\section{(c) (i) (2)}

La Revista Estudios es editada por la Universidad de Costa Rica y se distribuye bajo una Licencia Creative Commons Atribución-NoComercial-CompartirIgual 3.0 Costa Rica. Para más información envíe un mensaje a revistaestudios.eeg@ucr.ac.cr. 
"En 1921 Benjamin compró la acuarela de Paul Klee titulada: Angelus Novus. Por unos meses permanece en Münich en casa de G. Scholem y luego es llevada a Berlín. En 1932 Benjamin pensó en suicidarse y dejar de herencia la pintura a su amigo Scholem. En 1935 Benjamin emigra a París y lleva la pintura consigo. En 1940 antes de partir a los Pirineos para intentar escapar de los nazis deja la acuarela a resguardo de Bataille en la Biblioteca Nacional de París. Al terminar la Segunda Guerra Mundial es llevada a Estados Unidos en donde queda en manos de Theodor Adorno que a su regreso a Frankfurt la lleva consigo. En la actualidad la acuarela está en el Museo de Israel en Jerusalen. Fue legada por la viuda de Scholem". (Cfr. http://aquileana.wordpress.com/2008/06/28/walter-benjamina-proposito-del-angelus-novus-de-paul-klee/).

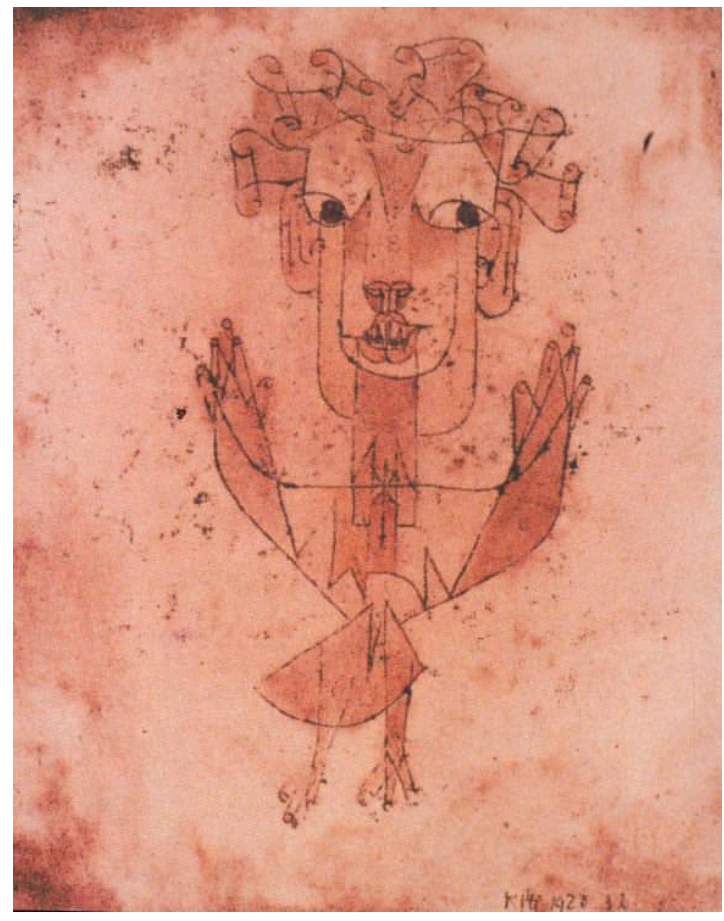

Paul Klee, Angelus Novus, 1920.

Extraído de

http://aquileana.wordpress.com/20

08/06/28/walter-benjamin-aproposito-del-angelus-novus-depaul-klee/) I de Julio del 2010

Angelus Novus representa, dialécticamente un caso muy interesante, dado que Klee ha proporcionado a Benjamin el soporte somático para la construcción de la tesis IX, que en su totalidad configura una poderosa imagen dialéctica, cuya comunicabilidad inmediata demanda su transcripción:

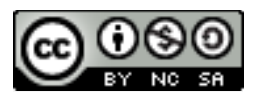

La Revista Estudios es editada por la Universidad de Costa Rica y se distribuye bajo una Licencia Creative Commons Atribución-NoComercial-CompartirIgual 3.0 Costa Rica. Para más información envíe un mensaje a revistaestudios.eeg@ucr.ac.cr. 
IX

Mi ala está pronta al vuelo, / vuelvo voluntariamente atrás, / pues si me quedase tiempo para vivir, / tendría poca fortuna.

GERHARD SCHOLEM: Saludo del Angelus

Hay un cuadro de Klee que se titula Angelus Novus. Se ve en él un ángel al parecer en el momento de alejarse de algo sobre lo cual clava la mirada. Tiene los ojos desencajados, la boca abierta y las alas tendidas. El ángel de la historia debe tener ese aspecto. Su cara está vuelta hacia el pasado. En lo que para nosotros aparece como una cadena de acontecimientos, él ve una catástrofe única, que acumula sin cesar ruina sobre ruina y se las arroja a sus pies. El ángel quisiera detenerse, despertar a los muertos y recomponer lo despedazado. Pero una tormenta desciende del Paraíso y se arremolina en sus alas y es tan fuerte que el ángel no puede plegarlas. Esta tempestad lo arrastra irresistiblemente hacia el futuro, al cual vuelve las espaldas, mientras el cúmulo de ruinas sube ante él hacia el cielo. Tal tempestad es lo que llamamos progreso.

Cfr. Benjamin, W. 1940/1967 pp. 46-47.

Las iluminaciones de Angelus Novus que Benjamin comparaba con relámpagos esféricos son, ciertamente incomprensibles en su concreción (la obra benjaminiana y su particular lectura del materialismo dialéctico e histórico) y se presentan en las tesis de forma constelacional. No obstante, es identificable, a lo largo de las tesis y que se expresa bellamente en esta imagen dialéctica, una suerte de principio sistemático: el derecho que el pasado tiene sobre nosotros, la memoria de la historia que coloca en primer plano el sufrimiento de los seres humanos. En la tesis IX, el ángel de la historia quisiera despertar (nuevamente reverbera el $\lambda$ yow heraclíteo) de su sueño a las víctimas del tiempo histórico entendido como continuum. La dialéctica de esta imagen se verifica en el momento en que el pasado carece de un punto privilegiado y accesible, sino que

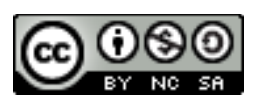

La Revista Estudios es editada por la Universidad de Costa Rica y se distribuye bajo una Licencia Creative Commons Atribución-NoComercial-CompartirIgual 3.0 Costa Rica. Para más información envíe un mensaje a revistaestudios.eeg@ucr.ac.cr. 
tiene su propia dinámica, su vida propia que le permite suspender el presente en cualquier momento, tal es su autonomía. En ese sentido para Benjamin el carácter de la revolución es la discontinuidad y no la continuidad, como advierte en la tesis XVI:

"El materialismo histórico no puede renunciar al concepto de un presente que no es tránsito sino que es inmóvil y se halla en equilibrio en el tiempo, puesto que dicho concepto define con precisión el presente en el cual él por su cuenta escribe historia. El historicismo postula una imagen "eterna" del pasado, el materialista histórico una experiencia única como éste. Deja que los otros agoten sus fuerzas en el burdel del historicismo con la meretriz "había una vez". Él permanece dueño de sus fuerzas: hombre suficiente para hacer saltar el continuum de la historia”. (Crf. Ibid. P. 50).

El componente epistémico de la memoria que es la que aprehende el pasado es fundamental, el ángel de la historia tiene su rostro vuelto hacia el pasado, y en el momento en que desea despertar a los muertos, quiere completar la exigencia dialéctica de concreción, quiere juntar lo destrozado. El paraíso que atenta contra esa exigencia dialéctica, lejos de ser una ilusión idílica, evita la construcción del tiempo-ahora (que hace saltar el tiempo homogéneo-vacío) y configura la experiencia del acontecer como estado de excepción. La tradición de los oprimidos enseña que "el estado de excepción en que vivimos es la regla" (Cfr. Ibid. p. 46) y la tarea del materialista es elaborar un concepto de historia a la altura de esa constatación.

Angelus Novus desmitifica una metafísica del progreso en donde las ruinas y las catástrofes son atribuidas a mecanismos autónomos, deterministas en donde desaparece su costo somático. Si la metafísica de la modernidad es sacrificial entonces hace sintagma con el mito. La desfetichización de la metafísica del progreso dentro de la cuales se enmarcan documentos/contextos como la revolución industrial, la revolución francesa, la república, la máquina de vapor, visibiliza la Historia como secuencia de producción de víctimas.

\section{(c) (i) (2)}

La Revista Estudios es editada por la Universidad de Costa Rica y se distribuye bajo una Licencia Creative Commons Atribución-NoComercial-CompartirIgual 3.0 Costa Rica. Para más información envíe un mensaje a revistaestudios.eeg@ucr.ac.cr. 
La imagen dialéctica que forma parte del análisis materialista en Benjamin, comporta además el elemento de distanciamiento respecto del patrimonio cultural:

"...la compenetración con el vencedor resulta cada vez más ventajosa para el amo del momento. Con lo cual se ha dicho suficiente respecto al materialismo histórico. Quien quiera haya conducido la victoria hasta el día de hoy, participa en el cortejo triunfal en el cual los dominadores de hoy pasan sobre aquellos que hoy yacen bajo tierra. La presa, como ha sido siempre la costumbre, es arrastrada en el triunfo. Se la denomina con la expresión: patrimonio cultural. Ėste deberá hallar en el materialista histórico un observador distante. Puesto que todo el patrimonio cultural que él abarca con la mirada tiene irremisiblemente un origen en el cual no puede pensar sin horror. Tal patrimonio debe su origen no sólo a la fatiga de los grandes genios que lo han creado, sino también a la esclavitud sin nombre de sus contemporáneos. No existe documento de cultura que no sea a la vez documento de barbarie. Y puesto que el documento de cultura no es en sí inmune a la barbarie, no lo es tampoco el proceso de la tradición, a través del cual se pasa de lo uno a lo otro, Por lo tanto, el materialista histórico se distancia en la medida de lo posible. Considera que su misión es la de pasar por la historia el cepillo a contrapelo" (Cfr. (Ibid. P. 46).

Cada expresión de imagen dialéctica (Goya, Grosz, Benjamin/Klee) contenida en este breve estudio ofrece un modelo de intervención, como solía decir Adorno, una forma de desmontar la patraña de la permanencia de una lógica sacrificial que se defiende a sí misma por medio de la ratio identificatoria. La imagen dialéctica verdadera, en Adorno es aquella que va más allá de sí misma y para ello tiene su auxilio en la dialéctica que moviliza sus contenidos en como un relámpago esférico (como diría Benjamin) capaz de atravesar el horizonte de lo pretérito como totalidad concreta. Este tipo de intervención supone una inmersión en el soporte somático de la imagen, pero también del objeto sociohistórico. Las implicaciones económico-sociales, políticas y libidinales que se condensan en el problema de la unilateralidad y autonomización de la ratio abstracta, que en su "pensarse" ahistórico/absoluto reemplaza su desarrollo en tanto que mediación necesaria entre la vida humana y la naturaleza, anuncian el arribo de los chiroptera y la noche del mundo que Goya combate, como lo hará Grosz, quien 
había advertido la racionalización del arte puro, en sentido freudiano como forma de reparación reaccionaria al servicio de la dominación y el afirmación de la autoridad, con lo cual anticipando una tesis fuerte en la estética frankfutiana: la no inocencia del arte (y desde luego, la imagen como una de sus manifestaciones) y la filosofía en su relación inextricable al interior de la omnipresencia de lo político. En cada caso, que bien podría servir como modelo de analítica dialéctica, el terreno de la imagen se convierte en campo de batalla, lo cual no es otra cosa que traer a primer plano al arte, y en este caso, la plástica como componente fundamental de una dialéctica negativa dentro de cuyos objetivos nucleares se encuentra la intervención materialista en el desmontaje del contexto de ofuscación general.

\section{Bibliografía}

Adorno, T.W. (1938/1991) Actualidad de la filosofía. Barcelona: Paidós.

Adorno, T.W. (1986) Dialéctica Negativa. Madrid: Taurus.

Adorno, T.W. (1951/2004) La teoría freudiana y el modelo de la propaganda fascista. En Escritos Sociológicos I. Madrid: Akal. Pp. 380-405.

Adorno, T.W. (2001) Minima moralia. Madrid: Taurus.

Bauer, O., Marcuse, H. et Al. (1967) Fascismo y capitalismo. Teorías sobre los orígenes sociales y función del fascismo. Barcelona: Martínez Roca.

Benjamin, W. (1940/1967) Tesis de la Filosofía de la historia. En Ensayos Escogidos. Buenos Aires: Sur. Pp. 43-52.

Buck-Morss, S. (1995) Dialéctica de la Mirada. Walter Benjamin y el proyecto de los Pasajes. Madrid: La Balsa de la Medusa. 
Revista Estudios, (37), 2018.

Diciembre 2018-Mayo 2019

ISSN 1659-3316

Fallas Vargas Fabrizio

Cinémarchives (2009) Photo, théâtre et cinéma : Raoul Walsh et lbsen. Extraído el 26 de Junio del 2010 de http://cinemarchives.hypotheses.org/689

Clubhausia (2010) Argumente gegen das Hofieren reaktion. Extraído el 26 de Junio del 2010 de http://clubhausia.fsrvv.de/?Zeitdokumente:Bilder

Entartete Kunst (2010). Extraído el 25 de Junio del 2010 de http://www.kassiber.de/entartete-kunst/

Foucault, M. (1978/2004) ¿Qué es la crítica? (Crítica y Aufklärung). En Foucault, M. Sobre la llustración (pp. 3-52). Madrid: Tecnos.

Grosz, G. (1925/1977) En lugar de una biografía. En Grosz, G. (1977) El rostro de la clase dominante \& iAjustaremos cuentas! Barcelona: Ed. Gustavo Gili.

Hegel, G.W.F. (2000) Enciclopedia de las Ciencias Filosóficas. Madrid: Alianza Editorial.

Horkheimer, M. - Adorno, T.W. (2001) Dialéctica de la llustración. Fragmentos filosóficos. Madrid: Trotta.

Kant, I. (1784/2004). Respuesta a la pregunta ¿Qué es la llustración? En http://kant.pais-global.com.ar/ Extraído el 10 de Mayo del 2010.

La audacia de Aquiles (2008) Walter Benjamin: A propósito del Angelus Novus, de Paul Klee. En http://aquileana.wordpress.com/2008/06/28/walter-

La Revista Estudios es editada por la Universidad de Costa Rica y se distribuye bajo una Licencia Creative Commons Atribución-NoComercial-CompartirIgual 3.0 Costa Rica. Para más información envíe un mensaje a revistaestudios.eeg@ucr.ac.cr. 
Revista Estudios, (37), 2018.

ISSN 1659-3316

Diciembre 2018-Mayo 2019 Fallas Vargas Fabrizio

benjamin-a-proposito-del-angelus-novus-de-paul-klee/ Extraído el 1 de Julio del 2010.

Mondolfo, R. (1973) Heráclito. Textos y problemas de su interpretación. México: Siglo XXI.

Muñoz, B. (1998) Dodecafonismo y sociedad de entreguerras. El reflejo del conflicto social en el Wozzeck de Alban Berg. En Reis, 84, 259-274.

Rodríguez, M. (Junio, 2010) Goyay "los sueños de la razón”. En Nota Uniandina, Universidad de los Andes. Quinta Ed.. Extraído el 25 de Junio del 2010 de http://notauniandina.edu.co/html/nota3/Goya.htm.

Wikipedia (2010) El sueño de la razón produce monstruos. En http://es.wikipedia.org/wiki/Archivo:El sueño de la razón produce monstr uos.jpg Recuperado el 14 de Mayo del 2010 a las 20:00 horas.

\section{(c) (1) 8 ()}

La Revista Estudios es editada por la Universidad de Costa Rica y se distribuye bajo una Licencia Creative Commons Atribución-NoComercial-CompartirIgual 3.0 Costa Rica. Para más información envíe un mensaje a revistaestudios.eeg@ucr.ac.cr. 